\title{
AS PERSPECTIVAS DA JUDICIALIZAÇÃO DA SAÚDE EM ÂMBITO MUNICIPAL E SUAS POSSIBILIDADES DE RESOLUÇÃO
}

\author{
Fábio Luis Borri ${ }^{1}$ \\ Vítor Sérgio Couto dos Santos ${ }^{2}$
}

\section{RESUMO:}

A Judicialização da Saúde não é um tema a ser abordado apenas sobre o aspecto jurídico, mas também como políticas de saúde e gestão da saúde. Quando garantido o direito ao cidadão brasileiro de ter acesso universal, integral e com equidade à saúde, muito se deve discutir para que esse direito, que por diversas vezes se torna uma política de saúde individualizada, não prejudique toda uma administração pública municipal e toda uma população local, uma vez que, o orçamento do Município é limitado e os direitos concedidos pelo Poder Judiciário ao cidadão em uma condenação contra este ente são, na verdade, de competência Estadual e/ou Federal. Dessa forma, ferramentas de gestão e jurídicas devem ser desenvolvidas para que não haja, na judicialização, prejuízo da coletividade em favor da individualidade.

Palavras-Chaves: Gestão Pública; Judicialização; Governo Municipal.

\begin{abstract}
:
The Judicialization of Health is not a topic to be addressed only on the legal aspect, but also as health policies and health management. When guaranteeing the right of the Brazilian citizen to have universal, integral and equitable access to health, much should be discussed so that this right, which in many cases becomes an individualized health policy, does not undermine an entire municipal public administration and a whole. local population, since the budget of the Municipality is limited and the rights granted by the Judiciary Power to the citizen in a conviction against this entity are, in fact, of State and/or Federal competence. Thus, management and legal tools should be developed so that there is no harm to the community in favor of individuality.
\end{abstract}

Keywords: Public Management; Judicialization; Municipal Government.

\footnotetext{
${ }^{1}$ Diretor de Planejamento, Gestão em Saúde e Fundo Municipal de Saúde da Secretaria Municipal de Saúde de Limeira/SP, Consultor Organizacional, Advogado, com MBA em Gestão Empresarial pela Fundação Getúlio Vargas - FGV e MBA em Gestão de Pessoas com Ênfase em Estratégias. Professor de graduação e pós-graduação no UNIFIA, Professor de Pós-graduação na UNIARARAS e USCS. Palestrante.

${ }^{2}$ Secretário de Saúde do Município de Limeira. Médico otorrinolaringologista. Especializado em Educação e Gestão de Serviços de Saúde pela Philadelphia International Medicine, Wharton School and Leonard Davis Institute of Health Economics of the University of Pennsylvania e FAAP - Fundação Armando Alvares Penteado. Ex-Docente na Faculade de Medicina de Teresópolis (RJ) e Faculdade de Fonoaudiologia da Fundação Pestalozzi (RJ).
} 


\section{INTRODUÇÃO}

Hoje em dia, muito tem-se falado em judicialização da saúde e o acesso que tem proporcionado às pessoas hipossuficientes. Esse acesso, que veremos em tópico específico, é um direito assegurado pela Carta Magna de nosso País, e, sem sombra de dúvidas, protege aqueles que mais necessitam da ajuda do Estado de ficarem às margens do acesso aos medicamentos, suplementos alimentares prescritos e serviços essenciais à sua sobrevivência.

Contudo, o direito à saúde, vista do ponto de vista do gestor municipal, possui três aspectos de grande relevância. O primeiro é assegurar ao munícipe, devido à sua hipossuficiência, aquilo que é necessário à sua saúde e sobrevivência dentro de um planejamento de gestão em que se verifica a possibilidade de integrar essa necessidade à rede municipal na atenção primária. Ou seja, medicamentos, exames, suplementos e serviços, que devido à uma demanda mais abrangente de pessoas necessitadas, são integradas ao fornecimento continuo e planejado.

O segundo aspecto é a criação de uma câmara pré-judicialização. Inúmeros casos existem em que os munícipes, que não são contemplados em políticas públicas de saúde e na distribuição de medicamentos, exames e serviços abrangidos pelo município, buscam o poder judiciário na figura do Defensor Público ou do Promotor Público (representante do MP Estadual) para buscar seus direitos através da judicialização dessa necessidade. Essa câmara pré-judicialização irá buscar a solução administrativa para o problema antes de ser distribuída a ação competente, e, caso atenda a demanda, não se faz necessário prosseguir na esfera judicial.

O terceiro e último aspecto abordado no presente trabalho e que deve ser estruturado a médio e longo prazo, inclusive com modificações na Lei Pátria, é, após a judicialização da demanda em saúde contra o município, em que, uma vez distribuída a ação judicial já não é mais possível a câmara anteriormente proposta, realizar a criação e implantação de uma audiência prévia ao deferimento ou indeferimento Liminar, o que evitará prejuízos para o demandante, para a população em geral e para a gestão pública através do melhor planejamento do orçamento.

Evidente, também, que o município não pode ficar arcando com uma demanda financeira proveniente de ações que deveriam ser contra outros entes governamentais, como Estado, Governo Federal (mesmo já tendo julgados no sentido de serem solidários) e saúde suplementar, como da mesma forma, não pode despender valores que em benefício de um prejudiquem a política pública de saúde como um todo. Dessa forma, devemos analisar a gestão da saúde, suas necessidades e possibilidades, principalmente buscando resolução dos problemas que podem ser gerados por essa falta de gestão. Ainda, como resolver o planejamento orçamentário através das políticas públicas de saúde. 


\section{DO DIREITO CONSTITUCIONAL À SAÚDE}

Em nossa Constituição Federal, a saúde está descrita como direito humano fundamental de natureza social, e, assim está no "Art. $6^{\circ}$. São direitos sociais a educação, a saúde, o trabalho, a moradia, o lazer, a segurança, a previdência social, a proteção à maternidade e à infância, a assistência aos desamparados, na forma desta Constituição.” Também em seu Art. 23, Inciso II, prescreve que, “Art. 23. É competência comum da União, dos Estados, do Distrito Federal e dos Municípios: II - cuidar da saúde e assistência pública, da proteção e garantia das pessoas portadoras de deficiência; ”.

A Carta Magna de 1988 assegura em seu art. 196 o direito à saúde como um direito de todos e um dever do Estado, ficando sua redação da seguinte forma: "Art. 196. A saúde é direito de todos e dever do Estado, garantido mediante políticas sociais e econômicas que visem à redução dos riscos de doença e de outros agravos e o acesso universal e igualitário às ações e serviços para sua promoção, proteção $e$ recuperação".

A Constituição é completada por inúmeros outros preceitos legais, inclusive pela Lei 8.080/90 que instituiu o Sistema Único de Saúde, que dispõe sobre as condições para a promoção, proteção e recuperação da saúde, assim como é responsável por descrever o conjunto de ações e serviços de saúde, prestados por órgãos e instituições públicas. Dentro desse contexto, temos o art. $2^{o}$ que reza: A saúde é um direito fundamental do ser humano, devendo o Estado prover as condições indispensáveis ao seu pleno exercício.

Nessa mesma Lei Ordinária, que cria o SUS, tivemos a definição de quais papeis cada ente governamental teriam no cumprimento da busca pela saúde, definindo o município como o responsável imediato pela saúde básica. Prescreve Henrique Hoffmann Monteiro Castro (2005) e citado no Artigo de Mariana Pretel: "Nesse âmbito, estabeleceu-se uma divisão de tarefas no que tange ao fornecimento de medicamentos, de maneira que o sistema básico de saúde fica a cargo dos Municípios (medicamentos básicos), o fornecimento de medicamentos classificados como extraordinários compete à União e os medicamentos ditos excepcionais são fornecidos pelos Estados. Percebe-se, claramente, a composição de um sistema único, que segue uma diretriz clara de descentralização, com direção única em cada esfera de governo".

Muito embora exista a divisão categoria entre cada ente governamental para a prestação, quem mais sofre com a judicialização é o município, e, diga-se de passagem, o elo mais fraco da corrente, pois é o de menor orçamento. Tendo em vista a preconizada necessidade urgente de assistência à saúde do indivíduo, este busca o amparo legal contra o município que é o ente mais próximo de sua realidade e isso já se tornou jurisprudência de solidariedade entre os entes políticos. O que veremos em item posterior. 


\section{A GESTÃO DA SAÚDE PELO MUNICÍPIO}

De acordo com o próprio Ministério da Saúde, “O Sistema Único de Saúde (SUS) é um dos maiores e mais complexos sistemas de saúde pública do mundo, abrangendo desde o simples atendimento para avaliação da pressão arterial, por meio da Atenção Primária, até o transplante de órgãos, garantindo acesso integral, universal e gratuito para toda a população do país... A gestão das ações e dos serviços de saúde deve ser solidária e participativa entre os três entes da Federação: a União, os Estados e os municípios. A rede que compõe o SUS é ampla e abrange tanto ações quanto os serviços de saúde. Engloba a atenção primária, média e alta complexidades, os serviços urgência e emergência, a atenção hospitalar, as ações e serviços das vigilâncias epidemiológica, sanitária e ambiental e assistência farmacêutica.”3

O Governo Municipal é responsável pelos seus habitantes, e, principalmente pelo hipossuficiente que necessita do SUS, na área da saúde. Nesse âmbito, temos que a Secretaria Municipal de Saúde é a responsável pelas ações e serviços de saúde, tanto na criação de políticas públicas, como na aplicação de políticas nacionais e estaduais que devem ser executadas. É a aplicação do SUS na municipalidade.

Dentro da organização e do planejamento do SUS na esfera municipal, podemos dividir em níveis de atenção à saúde em atenção básica, média e alta complexidade, vigilância em saúde e assistência farmacêutica. Nesse contexto, temos que a Atenção Básica foi definida como porta de entrada do sistema e centro ordenador das redes de atenção.

De acordo com a PORTARIA Nº 648, DE 28 DE MARÇO DE 2006, que, Aprova a Política Nacional de Atenção Básica, estabelecendo a revisão de diretrizes e normas para a organização da Atenção Básica para o Programa Saúde da Família (PSF) e o Programa Agentes Comunitários de Saúde (PACS), temos a seguinte definição para Atenção Básica: “A Atenção Básica caracteriza-se por um conjunto de ações de saúde, no âmbito individual e coletivo, que abrangem a promoção e a proteção da saúde, a prevenção de agravos, o diagnóstico, o tratamento, a reabilitação e a manutenção da saúde. É desenvolvida por meio do exercício de práticas gerenciais e sanitárias democráticas e participativas, sob forma de trabalho em equipe, dirigidas a populações de territórios bem delimitados, pelas quais assume a responsabilidade sanitária, considerando a dinamicidade existente no território em que vivem essas populações. Utiliza tecnologias de elevada complexidade e baixa densidade, que devem resolver os problemas de saúde de maior frequência e relevância em seu território. É o contato preferencial dos usuários com os sistemas de saúde. Orienta-se pelos princípios da universalidade, da acessibilidade e da coordenação do cuidado, do

\footnotetext{
${ }^{3}$ http://www.saude.gov.br/sistema-unico-de-saude
} 
vínculo e continuidade, da integralidade, da responsabilização, da humanização, da equidade e da participação social."4

Ainda, dando continuidade no entendimento sobre as responsabilidades municipais e do Distrito Federal com relação ao SUS, a mesma portaria citada acima, elenca categoricamente o que cada ente estatal deve realizar, cabendo, no que nos interessa nesse momento, sobre o município:

\section{“2.1 - Compete às Secretarias Municipais de Saúde e ao Distrito Federal:}

I - organizar, executar e gerenciar os serviços e ações de Atenção Básica, de forma universal, dentro do seu território, incluindo as unidades próprias e as cedidas pelo estado e pela União;

II - incluir a proposta de organização da Atenção Básica e da forma de utilização dos recursos do PAB fixo e variável, nos Planos de Saúde municipais e do Distrito Federal;

III - inserir preferencialmente, de acordo com sua capacidade institucional, a estratégia de Saúde da Família em sua rede de serviços, visando à organização sistêmica da atenção à saúde;

IV - organizar o fluxo de usuários, visando a garantia das referências a serviços e ações de saúde fora do âmbito da Atenção Básica;

$V$ - garantir infra-estrutura necessária ao funcionamento das Unidades Básicas de Saúde, dotandoas de recursos materiais, equipamentos e insumos suficientes para o conjunto de ações propostas;

$V I$ - selecionar, contratar e remunerar os profissionais que compõem as equipes multiprofissionais de Atenção Básica, inclusive os da Saúde da Família, em conformidade com a legislação vigente;

VII - programar as ações da Atenção Básica a partir de sua base territorial, utilizando instrumento de programação nacional ou correspondente local;

VIII - alimentar as bases de dados nacionais com os dados produzidos pelo sistema de saúde municipal, mantendo atualizado o cadastro de profissionais, de serviços e de estabelecimentos ambulatoriais, públicos e privados, sob sua gestão;

IX - elaborar metodologias e instrumentos de monitoramento e avaliação da Atenção Básica na esfera municipal;

$X$ - desenvolver mecanismos técnicos e estratégias organizacionais de qualificação de recursos humanos para gestão, planejamento, monitoramento e avaliação da Atenção Básica;

XI - definir estratégias de articulação com os serviços de saúde com vistas à institucionalização da avaliação da Atenção Básica;

XII - firmar, monitorar e avaliar os indicadores do Pacto da Atenção Básica no seu território, divulgando anualmente os resultados alcançados; 
XIII - verificar a qualidade e a consistência dos dados alimentados nos sistemas nacionais de informação a serem enviados às outras esferas de gestão;

$X I V$ - consolidar e analisar os dados de interesse das equipes locais, das equipes regionais e da gestão municipal, disponíveis nos sistemas de informação, divulgando os resultados obtidos;

XV - acompanhar e avaliar o trabalho da Atenção Básica com ou sem Saúde da Família, divulgando as informações e os resultados alcançados;

XVI - estimular e viabilizar a capacitação e a educação permanente dos profissionais das equipes; $e$

XVII - buscar a viabilização de parcerias com organizações governamentais, não governamentais e com o setor privado para fortalecimento da Atenção Básica no âmbito do seu território."

Como não podemos deixar de citar o desembolso de valores do município para cumprir com as responsabilidades Estaduais e Federais, que muitas vezes não são efetivadas diretamente, e, consequentemente geram a judicialização, convém expor suas responsabilidades naquilo que mais influencia o objeto do presente trabalho:

\section{“2.2 - Compete às Secretarias Estaduais de Saúde e ao Distrito Federal:}

IV - destinar recursos estaduais para compor o financiamento tripartite da Atenção Básica;

XII - ser co-responsável, junto ao Ministério da Saúde, pelo monitoramento da utilização dos recursos da Atenção Básica transferidos aos municípios e ao Distrito Federal;

\section{3 - Compete ao Ministério da Saúde:}

II - garantir fontes de recursos federais para compor o financiamento do Piso da Atenção Básica PAB fixo e variável."

A Atenção Básica tem como principal foco ser a porta de entrada do munícipe no SUS, o que nos leva a certeza de que seu funcionamento adequado acarreta a qualidade no atendimento das demandas de saúde e traz resolutividade aos problemas mais recorrentes da população. Se é garantida essa qualidade e resolutividade na Atenção Básica, a média e alta complexidade serão melhores planejadas e consequentemente o município sofrerá menos com judicializações.

Entre outras subdivisões do SUS municipal que passam pelo Fundo Municipal de Saúde, Vigilância Sanitária, Gestão do SUS etc., temos a Assistência Farmacêutica que é o conjunto de ações voltadas à promoção, proteção e recuperação da saúde, tanto individual como coletiva, tendo o medicamento como insumo essencial e visando assegurar a acessibilidade da população à farmacoterapia de qualidade e contribuir para o uso racional de medicamentos. Sendo ainda, incluído nesses programas os medicamentos alopáticos, homeopáticos, fitoterápicos e as plantas medicinais.

Quando falamos em financiamento das ações de Atenção Básica, a responsabilidade é dividida para os três entes políticos de gestão, ou seja, federal, estadual e municipal. “O Piso de Atenção Básica (PAB) 
constitui-se no componente federal para o financiamento da Atenção Básica, sendo composto de uma parte fixa e outra variável, denominadas, respectivamente, como PAB-Fixo e PAB-Variável. O PAB-Fixo refere-se ao financiamento de ações de Atenção Básica à Saúde, baseando-se no valor per capita por município. Já o PAB-Variável é constituído por recursos financeiros destinados ao financiamento de estratégias tais como Saúde da Família, Saúde Bucal, Nasf, Compensação de Especificidades Regionais, Saúde Indígena, entre outras, realizadas no âmbito da Atenção Básica em Saúde. O somatório das partes fixa e variável do PAB compõe o Teto Financeiro do Bloco da Atenção Básica. Os recursos do PAB são repassados mensalmente, de forma regular e automática, por meio do Fundo Nacional aos Fundos Municipais de Saúde, com informação disponibilizada no site: http://www.fns.saude.gov.br. Tais recursos não podem substituir as fontes de recursos próprios do orçamento municipal para a saúde"

Já a Média e Alta complexidade recebem valores diretamente através dos programas do MAC que vem da esfera Federal. Já o Estado repassa valores dos programas específicos, principalmente com relação aos medicamentos.

Nesse contexto, da divisão de funções e programas na área da saúde, podemos identificar os objetos de maior demanda judicial, seja pelo fato de falta de planejamento, por falta de recursos financeiros, por má gestão dos recursos, má vontade dos gestores, entre outros:

Serviços: Serviços com fisioterapia, fonoaudiologia, terapia ocupacional (atendimentos domiciliares, para crianças em sua maioria e métodos não convencionais), exames laboratoriais, exames de imagem, agendamento de consultas, óculos, cirurgias em geral etc.

Medicamentos: medicamentos padronizados na rede de atenção básica, medicamentos fornecidos por protocolo de alto custo, medicamentos fora da padronização da rede básica.

A origem dessa demanda pode vir de várias fontes que passamos a elencar:

a) médicos da própria rede que prescrevem medicamentos fora da padronização da rede básica ou de serviços que não possui o município em seus contratos com terceiros;

b) médico particulares, de convênio ou policlínicas populares que prescrevem medicamentos e serviços fora da padronização da rede básica;

c) falta dos medicamentos essenciais e que deveriam fazer parte das políticas públicas de saúde do município;

d) falta de serviços credenciados ou com contrato já licitado;

e) falta de medicamentos de protocolos de alto custo por culpa do fornecimento Estadual.

${ }^{5}$ http://bvsms.saude.gov.br/bvs/publicacoes/sus_municipio_garantindo_saude.pdf 
Fica claro, pela proposta de governo estabelecida juntamente com os planos municipais de saúde, assim como pela legislação Constitucional e Infraconstitucional, que a gestão municipal "deve garantir que a população sob sua responsabilidade tenha acesso à atenção básica e aos serviços especializados (de média e alta complexidade), mesmo quando localizados fora de seu território, controlando, racionalizando e avaliando os resultados obtidos."

Logo, descoberta a origem do problema e suas principais fontes, basta ao município buscar as possibilidades de solução para que não exista necessariamente a judicialização, e, se houver, que siga no caminho de incorporar tais medicamentos e serviços em sua rede, quando de sua competência. Assim, apontamos soluções de gestão voltadas para as demandas acusadas acima, tais como:

a) manutenção de estoque com todos os medicamentos necessários na rede básica de saúde;

b) programa de controle e gestão dos medicamentos de alto custo em parceria com o Estado Federado por meio da DRS competente;

c) gestão e controle de serviços necessários à população local que já tenha histórico de pedidos;

d) orientação via protocolo dos médicos da rede para prescrição dos medicamentos existentes na rede básica e que são comprovadamente eficazes para determinadas doenças;

e) orientação via protocolo dos médicos da rede para prescrição de tratamentos existentes na rede básica e que são comprovadamente eficazes para determinadas doenças;

f) orientação via protocolo para que os médicos, ao prescreverem medicamentos fora do fornecimento da rede básica, atestem com comprovação científica reconhecida mundialmente (medicina baseada em evidências);

g) revisão periódica do rol de medicamentos da rede, com a inclusão, sob critério de evidência médica de novos medicamentos e tecnologias;

h) revisão anual do Plano Municipal de Saúde, com a adaptação das políticas de saúde aos avanços da medicina.

As possibilidades administrativas devem ser analisadas caso a caso para que sejam adequadas no orçamento municipal, que muitas vezes, não comportam sequer as demandas já programadas em exercícios anteriores e aprovadas na LDO (Lei de Diretrizes Orçamentárias) e na LOA (Lei Orçamentária Anual).

$\mathrm{O}$ orçamento municipal bem planejado parte de um pressuposto base zero, ou seja, deve existir uma eficiente gestão de custos. Busca-se com isso, dentro das muitas variáveis e circunstâncias fáticas, uma resolução do problema orçamentário com o total conhecimento das necessidades e demandas.

\footnotetext{
${ }^{6}$ http://bvsms.saude.gov.br/bvs/publicacoes/sus_municipio_garantindo_saude.pdf
} 


\section{CÂMARA PRÉ-JUDICIAL}

Duas propostas são elencadas no presente trabalho, a primeira, e que deverá ser apurada em outros estudos ainda mais específicos, é a criação de uma câmara técnica que servirá de apoio para antecipar e evitar a judicialização dos casos da saúde. A segunda proposta está ligada a mudança da Lei Processual conforme veremos em tópico específico.

A câmara técnica é uma construção administrativa da própria prefeitura municipal e que auxiliará o juízo de forma anterior ao ajuizamento. É uma parceria entre a gestão municipal e o poder Judiciário Estadual.

Deixamos claro que a mesma câmara administrativa, poderá ser utilizada para apreciação dos casos judicializados, mas para tanto, a Lei deverá ser acrescida com embasamento nesse artigo e posterior projeto de Lei.

Hoje temos a experiência prática que está sendo realizada no Município de Limeira, entre outros municípios, onde o usuário do SUS chega no fórum com uma demanda não atendida pelo município ou Estado e procura pelo MP ou pelo Defensor Público.

Este ente relata qual a demanda em formulário competente, e, encaminha para o setor de judicialização criado no município e gerenciado pela Secretaria Municipal de Saúde em parceria com a Secretaria de Assuntos Jurídicos, composto por farmacêutica, enfermeira e procurador municipal, para que tal demanda seja atendida no prazo estabelecido, se não ocorre esse cumprimento, o usuário retorna ao fórum e é distribuída a ação. Caso o município atenda sua demanda, é evitada a judicialização e consequente encarecimento pela movimentação do judiciário.

Buscamos com essas experiências, e novos conhecimentos teóricos, aprofundar a criação da câmara técnica completando com adição do profissional médico perito, e, ainda, levar a câmara técnica para dentro do fórum de cada município, propiciando maior rapidez e assertividade no atendimento.

A câmara técnica funcionaria da seguinte forma:

a) O usuário SUS vai até o fórum e procura pelo agente do Ministério Público ou pelo Defensor Público;

b) O Douto Promotor, ou Defensor Público, faz o primeiro atendimento e encaminha a demanda para a câmara técnica, que estará alocada no próprio fórum, requerendo posicionamento;

c) A câmara técnica analisa o pedido, verificando a existência de atendimento dentro da rede de atenção básica; 
d) Existindo a possibilidade de atendimento pela já existência de medicamentos, suplementos, exames ou cirurgias pactuadas pelo município, a câmara técnica encaminha o usuário para secretaria para agendamento ou retirada do produto;

e) Caso não haja o direito em questão disponibilizado pelo SUS, seja por falta de compra ou contrato (convênio) a Secretaria de Saúde deverá pedir prazo para atendimento através do seu procurador municipal, e, agendar posterior cumprimento do que fora demandado;

f) $\mathrm{Na}$ inexistência e/ou impossibilidade de cumprimento do objeto que se demanda, pelo próprio engessamento dos processos administrativos do poder público, a câmara técnica retorna o usuário ao MP ou Defensoria com parecer técnico sobre a impossibilidade de cumprimento e indicação de seguimento do ajuizamento, inclusive com indicação do ente político que deverá ser demandado solidariamente;

g) Caso haja a verificação de novas tecnologias não autorizadas pela ANVISA, a câmara técnica retorna parecer ao MP ou defensor, indicando a irregularidade técnica existente a indicação para que seja acostada ao processo administrativo o embasamento pela medicina baseada em evidências (MBE) principalmente com a utilização do CONITEC (Comissão Nacional de Incorporação de Tecnologias no Sistema Único de Saúde);

h) A câmara técnica também irá fornecer parecer quando o pedido esteja em desacordo com os protocolos médicos, ou da área da saúde, existentes, recusando a demanda e emitindo parecer técnico a quem requereu a câmara;

i) O município disponibiliza o corpo técnico composto por:

I. Médico(a) Perito(a);

II. Enfermeiro(a);

III. Farmacêutico(a);

IV. Procurador(a) Municipal;

V. Auxiliar administrativo.

j) O município arcará com os custos da composição da Câmara Técnica, inclusive com a formatação das escalas de trabalho de acordo com órgão de classe competentes ou concursos e contratações diretas;

k) A Câmara Pré-Judicial deverá ser acordada entre o ente político municipal e o Poder Judiciário do Estado que pertence, ao contrario do que está sendo proposto abaixo com a utilização da mesma câmara nas audiências preliminares, no que tange ao pedido de tutela de urgência com pedido liminar; 
1) No caso de demanda em que o particular ingressa com advogado próprio, a câmara não poderá ser utilizada de forma administrativa, uma vez que, a ação já fora distribuída e está em fase de apreciação da exordial;

m) No caso acima exposto, a demanda deverá ser encaminhada para a câmara apenas no caso de pedido liminar, onde seguirá o trâmite abaixo exposto;

n) A câmara técnica deverá trabalhar com imparcialidade e embasada em preceitos legais e éticos do setor competente, usos e costume.

\section{NAT-JUS NO ESTADO DE SÃO PAULO}

O Núcleo de Apoio Técnico do Poder Judiciário foi um importante passo quando tratamos da judicialização da Saúde, pois passa a dar melhor embasamento teórico para as decisões do magistrado.

Segundo a descrição do Tribunal de Justiça do Estado de São Paulo: “O NAT-Jus é um projeto do Conselho Nacional de Justiça (CNJ), que prevê a criação dos Núcleos de Apoio Técnico do Poder Judiciário (NAT-Jus) vinculados aos tribunais para subsidiar os magistrados em ações judiciais na área de saúde. Ao receber uma ação que envolva questões de saúde, o juiz pode encaminhar uma solicitação por e-mail ao NAT-Jus para uma análise técnica, juntamente com a petição inicial, o formulário para informação técnica preenchido pelo assessor do magistrado ou pela parte (advogado ou médico), relatório clínico atualizado, prescrição de procedimento, receita e exames médicos. Os servidores do TJSP que atuam no setor avaliam os documentos e a especialidade. A depender do caso, enviam a solicitação para o Núcleo de Avaliação de Tecnologia em Saúde de uma das instituições conveniadas ou para a própria equipe técnica do TJ, composta por uma médica e uma enfermeira, elaboram a nota ou resposta. São três tipos de informações: - Resposta técnica-prazo de 72 horas; - Nota técnica - prazo de sete dias úteis (análises que demandam estudos mais aprofundados e revisão bibliográfica); - Parecer técnico - 90 dias (análises de casos mais complexos); - A resposta é enviada para o NAT-Jus, que repassa ao magistrado do caso. ",

A conjugação de um parecer técnico na área da saúde trás informações anteriormente desconhecidas pelos magistrados, que em sua maioria, tem trabalhado com a Lei Constitucional e Infraconstitucional para embasar suas decisões, principalmente as Liminares. Ou seja, argumentam o direito universal à saúde, sem embasamento da necessidade real de determinado tratamento ou medicamento.

\footnotetext{
${ }^{7}$ https://www.tjsp.jus.br/NatJus
} 
Com relação a esse assunto, temos visto ainda, magistrados concederem liminar em ações que são munidas apenas de prescrição médica, e, muitas vezes, de medicamentos ou tratamentos que não são aprovados/registrados pela ANVISA. Ora, muito embora seja inviável e até ilegal tal concessão, é possível que exista soluções na medicina de evidência, desenvolvimento do assunto pelo CONITEC (Comissão Nacional de Incorporação de Tecnologias no Sistema Único de Saúde) etc.

Com o NAT-Jus muito foi feito nesse contexto e muito já adiantou com relação aos pareceres necessários para o embasamento técnico citado. Contudo, o prazo necessário ainda é insatisfatório dentro do que poderá ser feito com um novo posicionamento do Poder Judiciário, como veremos no tópico abaixo, onde é feita nova proposta de audiências anteriores ao deferimento da Liminar, em tempo simultâneo ao que seria o julgamento dessa.

\section{CRIAÇÃO DE UMA AUDIÊNCIA PRELIMINAR COM CÂMARA TÉCNICA}

Como já foi dito, o principal foco do SUS é atender àquele que tem maior necessidade, o hipossuficiente. É com essa finalidade que todos estão preocupados e empenhados, pois a saúde, como já descrito em diversos trechos e em diversos artigos, é direito de todos e um dever do Estado.

Mas, como já vimos anteriormente, existe um grande problema no que se refere à assistência que os entes políticos devem conceder às pessoas de seu território, como por exemplo, a deficiência financeira, a falta de gestão etc.

Assim, tendo em vista de um lado o dever do Estado em atender os direitos fundamentais, e, de outro lado as necessidades e carências existentes na área da saúde pública, entendemos que na falta da devida prestação desses serviços e a prioridade de atendimento, faz-se necessário a judicialização da saúde em sua forma mais plena.

A Judicialização tem o aspecto positivo quando atende à demanda de quem realmente necessita, mas não é só isso que ocorre e que temos visto na prática. Muitas pessoas com poder aquisitivo estão se valendo da judicialização para adquirir medicamentos ou tratamentos que poderiam fazer por meios privados. E não é só isso, existe uma grande gama de médicos e outros profissionais da saúde que atendem pela rede suplementar de saúde, ou, por meio particular, e que indicam a judicialização para buscar tratamentos, medicamentos e serviços do SUS, ou ainda, estamos tendo um grande número de judicializações de novas tecnologias, medicamentos e serviços que ainda não estão no rol do SUS.

Nesse sentido, o douto magistrado Clenio Jair Schulze escreve sobre novas tecnologias ainda não incorporadas no SUS: 
"Importante inovação trazida com a Lei 12.401/11 (Brasil, 2011) foi a incorporação definitiva da Medicina Baseada em Evidências (BEM) no sistema jurídico pátrio. Com efeito, a partir da MBE, torna-se necessária a observância de alguns requisitos à incorporação de novas tecnologias no âmbito do SUS. Vale dizer que se deve verificar a existência de evidências científicas sobre eficácia, a acurácia, a efetividade e a segurança do medicamento, produto ou procedimento objeto do processo de incorporação" ${ }^{\prime}$.

Esse conceito nos faz refletir não apenas sobre as novas tecnologias, mas a verificação da medicina baseada em evidências em vários formatos, inclusive na formatação de um novo procedimento judicial com relação às ações distribuídas com objeto principal SUS.

A maior parte das judicializações já vem escritas com pedido liminar, e, muitas vezes instruídas apenas com a prescrição médica, são deferidas imediatamente, mesmo sem comprovação científica de sua eficácia, já que não aprovadas pela ANVISA ou que não estão elencadas no SUS, RENAME. Outros pedidos, mesmo que tendo aprovação técnica, não são necessariamente o melhor ou o único caminho para o Requerente/Paciente acudir sua necessidade. Lembrando que, o Município possui uma limitação orçamentaria muito maior que os outros entes políticos (Estado e Federação) e geralmente é o único condenado, já que está claro a posição jurisprudencial sobre a solidariedade dos entes.

Logo, se ultrapassada a solução de uma câmara pré-judicial de conciliação administrativa, como vem sendo realizada no município de Limeira/SP entre outros, entendemos que se faz necessário a realização de uma audiência de conciliação, mesmo anterior ou concomitante ao pedido liminar.

Quando falamos em Audiência preliminar de conciliação ou mediação - Novo CPC (Lei nº 13.105/15) temos o seguinte conceito:

"Será de conciliação nos casos em que não houver vínculo anterior entre as partes; será de mediação nos casos em que, ao contrário, houver vínculo anterior entre as partes. Diferentemente do CPC/1973, a audiência de conciliação ou mediação será realizada antes do oferecimento da defesa. Trata-se, pois, de audiência preliminar. Será realizada no centro judiciário de solução consensual de conflitos; somente em casos excepcionais ocorrerá na sede do juízo. A audiência pode realizar-se por meio eletrônico, como sistema de videoconferência. Poderá haver mais de uma sessão destinada à conciliação e à mediação, não excedentes a dois meses da primeira, desde que necessárias à composição das partes. A pauta das audiências de conciliação ou de mediação será organizada para respeitar o

\footnotetext{
${ }^{8}$ GENTILLI, Raquel de Matos Lopes, et al. Direito da Saúde em Perspectiva: Judicialização, Gestão e Acesso. 1a Ed. Vitória: Editora Emescam, 2016.
} 
intervalo mínimo de vinte minutos entre o início de uma e o início da seguinte. Deverá ser conduzida por conciliador ou mediador, conforme o caso. Se não houver conciliador ou mediador, em caráter excepcional, poderá ser conduzida pelo juiz. A audiência não será realizada se ambas as partes manifestarem, expressamente, desinteresse na composição consensual; ou quando não se admitir a autocomposição. O autor deverá indicar, na petição inicial, seu desinteresse na autocomposição, e o réu deverá fazê-lo, por petição, apresentada com 10 (dez) dias de antecedência, contados da data da audiência. Havendo litisconsórcio, o desinteresse na realização da audiência deve ser manifestado por todos os litisconsortes." "9

Essa audiência de conciliação proposta pelo CPC pode ser tardia quando falamos em saúde, tanto para o município como para o paciente. Expliquemos melhor, mas antes a descrição do artigo que reza sobre a dita audiência.

A Lei n. 13.105 de 16 de março de 2015, que instituiu o atual Código de Processo Civil, dispõe no artigo 334, do capítulo V, sobre a audiência de conciliação ou mediação, a chamada audiência preliminar: “Art. 334. Se a petição inicial preencher os requisitos essenciais e não for o caso de improcedência liminar do pedido, o juiz designará audiência de conciliação ou de mediação com antecedência mínima de 30 (trinta) dias, devendo ser citado o réu com pelo menos 20 (vinte) dias de antecedência.

$\S 1^{\circ}$ O conciliador ou mediador, onde houver, atuará necessariamente na audiência de conciliação ou de mediação, observando o disposto neste Código, bem como as disposições da lei de organização judiciária.

$\S 2^{\circ}$ Poderá haver mais de uma sessão destinada à conciliação e à mediação, não podendo exceder a 2 (dois) meses da data de realização da primeira sessão, desde que necessárias à composição das partes.

$\S 3^{\circ}$ A intimação do autor para a audiência será feita na pessoa de seu advogado.

$\S 4^{\circ}$ A audiência não será realizada:

I - se ambas as partes manifestarem, expressamente, desinteresse na composição consensual;

II - quando não se admitir a autocomposição.

\footnotetext{
${ }^{9}$ https://www.direitonet.com.br/dicionario/exibir/1628/Audiencia-preliminar-de-conciliacao-ou-mediacao-Novo-CPC-Leino-13105-15
} 
$\S 5^{\circ} \mathrm{O}$ autor deverá indicar, na petição inicial, seu desinteresse na autocomposição, e o réu deverá fazê-lo, por petição, apresentada com 10 (dez) dias de antecedência, contados da data da audiência.

$\S 6^{\circ}$ Havendo litisconsórcio, o desinteresse na realização da audiência deve ser manifestado por todos os litisconsortes.

$\S 7^{\circ}$ A audiência de conciliação ou de mediação pode realizar-se por meio eletrônico, nos termos da lei.

$\S 8^{\circ}$ O não comparecimento injustificado do autor ou do réu à audiência de conciliação é considerado ato atentatório à dignidade da justiça e será sancionado com multa de até dois por cento da vantagem econômica pretendida ou do valor da causa, revertida em favor da União ou do Estado.

$\S 9^{\circ}$ As partes devem estar acompanhadas por seus advogados ou defensores públicos.

$\S 10$. A parte poderá constituir representante, por meio de procuração específica, com poderes para negociar e transigir.

§ 11. A autocomposição obtida será reduzida a termo e homologada por sentença.

§ 12. A pauta das audiências de conciliação ou de mediação será organizada de modo a respeitar o intervalo mínimo de 20 (vinte) minutos entre o início de uma e o início da seguinte."

Voltemos ao que foi dito sobre o prejuízo. Se a audiência de conciliação é posterior ao deferimento ou não do pedido liminar, esse poderá gerar prejuízo à saúde e a vida do paciente se não for atendido, e, poderá gerar prejuízo para o município se o pedido não estiver devidamente embasado, ou a eficácia não ser condizente com o que já existe de protocolo no SUS.

Dessa forma, idealizamos um novo procedimento quando da existência de pedido liminar voltado para a área da saúde, buscando medicamentos, exames e tratamentos que não foram atendidos em câmara préjudicialização.

Acreditamos que os pedidos poderão ser compostos de maneira mais eficaz.

O procedimento seria da seguinte forma:

a) Os pedidos realizados ao MP ou à Defensoria Pública deverão ser passados por uma câmara préjudicial onde o município verificará a possibilidade de atendimento da demanda, conforme descrito em item anterior;

b) Os pedidos vindos diretamente de advogados particulares ou de organizações/entidades, deverão ser distribuídos e já direcionados para uma audiência preliminar de conciliação; 
c) Na audiência de conciliação, deverão estar presentes as partes, magistrado, membro do Ministério Público quando necessário, e uma câmara técnica composto por:

I. Médico(a) perito(a);

II. Farmacêutico(a);

III. Enfermeiro(a);

IV. Procurador Municipal.

d) Presentes as partes acima expostas, o juiz concede à câmara técnica (composta por membros do município, que arcará com os valores de seus pagamentos) o prazo de 30 minutos para análise e 30 minutos para apresentar parecer técnico sobre o pedido, onde será analisado a prescrição com relação aos sintomas e, se houver, exames apresentados;

e) Com base no parecer técnico, o magistrado irá tomar a decisão sobre o deferimento ou não da tutela de urgência antecipada liminarmente;

f) Dada a decisão, o processo corre pelo procedimento competente.

Para finalizar esse tópico pode ser acrescentado que a câmara técnica para o acompanhamento e fornecimento do parecer no caso de pedido liminar, com uma nova audiência preliminar, poderá ser a mesma da câmara pré-judicial, uma vez que estará presente no fórum pelo período que forem analisados os pedidos.

No caso em pauta não estamos propondo o fim do NAT-Jus, pelo contrário, estamos propondo completar e dar mais embasamento às decisões judiciais que são proferidas nesse contexto. Nenhuma decisão sobre a Liminar irá travar o desenvolvimento do processo.

Não existirá injustiça ou falta de atendimento, pois a equipe será imparcial em seu parecer, e, havendo necessidade do cumprimento imediato, a mesma deverá indicar a necessidade iminente.

\section{AÇÕES REGRESSIVAS}

As ações que são propostas, geralmente, contra o município e Estado na esfera da saúde podem leva o primeiro à um prejuízo financeiro que não estava anteriormente planejado em seu orçamento, obrigandoo a assumir uma responsabilidade do Governo Federal ou do Estado Federado. Contudo, o artigo 35, Inciso VII, da Lei n. 8.080/90 prevê a possibilidade de ações que visem o ressarcimento do município das despesas despendidas resultantes do atendimento à demanda decorrente de serviços prestados ou produtos fornecidos para suprir a deficiência de outros entes governamentais. 
Não só contra outros entes políticos, mas principalmente contra a saúde suplementar. Os planos de saúde muitas vezes direcionam seus cooperados/clientes para o SUS, economizando assim em exames e tratamentos prescritos por seus médicos.

Assim, podemos ter dois caminhos, ou são envolvidos no processo ou o ente político ingressa com a devida ação regressiva para se ressarcir dos prejuízos impostos pelo poder judiciário em conformidade com a necessidade do paciente.

E para finalizar o entendimento sobre ação regressiva, que deverá ser objeto de um novo artigo, temos que: "É fundada no direito de uma pessoa (direito de regresso) de haver de outrem importância por si despendida ou paga no cumprimento de obrigação, cuja responsabilidade direta e principal a ele pertencia. A ação tem por objetivo reaver a soma despendida nessa reparação da pessoa cujo dano foi por ela, individualmente, causado" $"$.

Assim sendo, qualquer judicialização que não seja de competência do ente municipal, sua obrigação direta, mesmo que respondendo solidariamente como vem sendo categoricamente julgado nos Tribunais, o procurado municipal deverá estudar a possibilidade de ingresso da ação regressiva, e, julgando pela viabilidade do pedido, judicializar.

Em todos os casos de judicialização da saúde que são originárias, de alguma forma, pelo plano de saúde ou como conhecemos, saúde suplementar, deverão ser estudas com urgência e apresentadas as iniciais de regressivas para distribuição.

\section{CONCLUSÃO}

Tendo em vista ao Direito Constitucional à Saúde que todas as pessoas possuem, e, o dever do Estado em atender essa demanda, fica evidente que necessário é a prestação de serviços e o fornecimento de produtos no que compete ao SUS.

Contudo, existem soluções para que essa prestação não seja mal utilizada ou até mesmo não cumprido com o consequente prejuízo do usuário SUS.

Entre as soluções propostas no presente artigo temos a melhora na gestão do SUS, pelas próprias secretarias municipais de saúde, a criação da parceria entre prefeitura municipal (SMS) e Poder Judiciário com a utilização de uma câmara técnica administrativa, e, a modificação da Lei Processual Civil com a criação de uma audiência preliminar com participação e até mesmo fundamentação da Câmara Técnica (a mesma utilizada administrativamente), onde, todas as ações que possuem como objeto a saúde através do atendimento SUS terão um parecer técnico.

${ }^{10}$ http://www.cnmp.mp.br/portal/glossario/8254-acao-regressiva 
No caso de as alternativas anteriores restarem prejudicadas de alguma forma, o Poder Judiciário ainda contará com o auxilio do NAT-Jus já criado e em fase de implantação.

O que mais importa em todo contexto apresentado é o atendimento ao mais necessitados, ao usuário do SUS, que, por hipossuficiência não tem condições de prover seu sustento e a manutenção da sua saúde e até da própria vida.

Como fator limitante do bom desempenho do sistema, devemos ressaltar a importância do papel do Gestor Municipal na elaboração das políticas públicas e sua adequação ao orçamento aprovado, e, com a contribuição do Conselho Municipal de Saúde. Além do mais, quantificar as demandas judiciais no que tange ao não cumprimento das políticas aprovadas, as demandas que extrapolam as políticas públicas e as demandas exóticas ou atípicas.

\section{REFERÊNCIA BIBLIOGRÁFICA}

CASTRO, Henrique Hoffmann Monteiro de. Do direito público subjetivo à saúde: conceituação, previsão legal e aplicação na demanda de medicamentos em face do Estado-membro. Disponível em http://jus2.uol.com.br/doutrina/texto.asp?id=6783 Acesso em 17.mar.2010.

Manual do(a) Gestor(a) Municipal do SUS: "Diálogos no Cotidiano" / CONASEMS. COSEMSRJ, LAPPIS/IMS/UERJ - Rio de Janeiro: CEPESC/IMS/UERJ, 2016.

http://bvsms.saude.gov.br/bvs/publicacoes/sus_municipio_garantindo_saude.pdf

http://www.saude.gov.br/sistema-unico-de-saude

http://189.28.128.100/dab/docs/legislacao/portaria_648_28_03_2006.pdf

https://www.direitonet.com.br/dicionario/exibir/1628/Audiencia-preliminar-de-conciliacao-oumediacao-Novo-CPC-Lei-no-13105-15

GENTILLI, Raquel de Matos Lopes, et al. Direito da Saúde em Perspectiva: Judicialização, Gestão e Acesso. $1^{\text {a }}$ Ed. Vitória: Editora Emescam, 2016.

João Pedro Gebran Neto, Clenir Sani Avanza, Gabriel Schulman (org.). Direito da Saúde em Perspectiva: Judicialização, Gestão e Acesso. Vitória: Editora Emescam, 2017. Vol. 2.

João Pedro Gebran Neto, Clenir Sani Avanza, Gabriel Schulman (org.). Direito da Saúde em Perspectiva: Judicialização, Gestão e Acesso. Vitória: Editora Emescam, 2018. Vol. 3.

http://www.cnmp.mp.br/portal/glossario/8254-acao-regressiva 